\title{
OS TRÊS MOMENTOS PEDAGÓGICOS COMO PRÁTICA INCLUSIVA: UMA EXPERIÊNCIA COM LEIS DE NEWTON ${ }^{*}$
}

Carlos Ivan Falcão Fehlberg ${ }^{1}$

\section{AMBIENTAÇÃO}

O presente trabalho se passa em um cursinho preparatório para o processo seletivo de cursos técnicos integrados ao ensino médio do Ifes (Instituto Federal do Espírito Santo), voltado para alunos do último ano do Ensino Fundamental e primeiro do Médio. O cursinho possui um caráter inclusivo, atendendo alunos de escolas públicas municipais da cidade de Vitória localizadas em bairros periféricos com vários jovens e crianças em situação de vulnerabilidade social.

O caráter inclusivo é nato do projeto, haja visto ele ser nascido de movimentos sociais de luta pela educação desenvolvidos em Vitória há vários anos. Construído de forma voluntária e gratuita, o Pré-Ifes "Vitória" é fruto de muito trabalho conjunto e colaborativo, nascido em discussões e anseios dentro do pré-Enem desenvolvido pela Associação Atitude desde 2002, e que vem sendo elaborado e aprimorado desde 2016.

Os alunos em geral possuem acentuadas dificuldades e poucos participam das aulas de forma ativa. É desenvolvido ao longo de todo o ano um trabalho para a desinibição desses alunos, através de jogos didáticos, aulas interdisciplinares, acompanhamento pedagógico e afins. Todas essas atividades produzem resultados vistosos. Dentro dessa perspectiva, mesmo uma aula "normal" pode ser transformada em um ato de inclusão, como o que será aqui relatado.

${ }^{*}$ DOI - 10.29388/978-65-86678-08-6-0-f.47-52

${ }^{1}$ Pré-Ifes "Vitória”. E-mail: ciffehlberg@gmail.com 


\section{CONTEÚDO}

O conteúdo a ser abordado na experiência relatada foi o das Leis de Newton. Sendo de extrema importância no processo seletivo pleiteado, era fundamental uma abordagem efetiva em aprendizagem, tanto conceitual como operacional, na resolução de exercícios, mas também que permitisse a participação ativa dos alunos durante a aula e sua ação em grupo na construção do conhecimento, buscando criar um modo de pertencimento, tanto ao projeto, como a uma comunidade colaborativa.

Mesmo as Leis de Newton estando envolvidas em fenômenos cotidianos, seu formalismo matemático e suas abstrações e idealizações nos modelos as deixam nada triviais. Portanto, seria necessária uma abordagem conceitual anterior ao trabalho matemático, que permitisse o confronto entre o senso comum e o que era esperado pela teoria da mecânica newtoniana, tanto de forma conceitual como em primeiras aparições matemáticas.

\section{METODOLOGIA}

A metodologia escolhida foi a dos três momentos pedagógicos (3MP), como apresentada por Demétrio Delizoicov e José André Angotti, devido a sua possibilidade de uso do cotidiano, através da problematização e a sua facilidade de interação de grupo durante as aulas.

Ela parte da ideia epistemológica de que o problema é o gerador do conhecimento, mas se aprofunda na discussão do que seja o problema. Vai além do uso comum, e insere o termo problematização para separar. Nesta, um problema geral do cotidiano do aluno, que causa a ele a necessidade de solução, é apresentado de forma a motivar a aprendizagem e a encontrar conhecimentos que os alunos já possuam e usam para resolver problemas. Após a problematização, o professor exibe aos alunos que seus conhecimentos não dão conta de todos os elementos do problema, chegando o momento da organização, 
onde os conceitos científicos são levantados, discutidos e aprofundados. Ao final desta, o aluno passa a lidar com outras situações onde aqueles conceitos se aplicam, sempre na perspectiva de construção e solução de problemas (DELIZOICOV, 2001).

\section{PRÁTICA}

Foi construído um material didático, consistindo de elementos para os três momentos que aconteceram em duas aulas.

Para a problematização foram apresentadas imagens de situações cotidianas (brincadeiras, paisagens) onde o estudante era questionado sobre como "força" se relacionava com a imagem e o porquê. Para isso os estudantes foram deixados a sós em sala por alguns minutos, para que a presença do professor não inibisse a apresentação de quaisquer conceitos. Com a volta do professor, continuou a problematização, perguntando aos alunos sobre suas soluções às imagens e o que eles queriam dizer com a ideia de força que haviam denotado nas soluções. Ao longo da problematização, os conceitos apresentados que possuíam falhas estruturais eram confrontados pelo professor, questionando com contra exemplos.

$\mathrm{Na}$ mesma aula começamos a organização, onde eram construídas as soluções corretas e junto a elas a conceituação de força. Duran te as discussões conceituais, surgiam elementos que iam permitindo a relação com o conteúdo já estudado de Cinemática e abriam espaço para a formalização matemática das Leis de Newton.

A organização continuou na segunda aula, onde continuamos a solução das situações e conceituação de força, além de mais discussões sobre o caráter matemático. Em todos os momentos, a solução correta era obtida por meio do diálogo com os alunos e entre eles, por meio de apresentações das soluções e discussão (figura 1). Não coube ao professor impor a solução, mas sim construí-la com os alunos, como previsto pelo método. 
Figura 1. Aluna apresenta solução para colegas

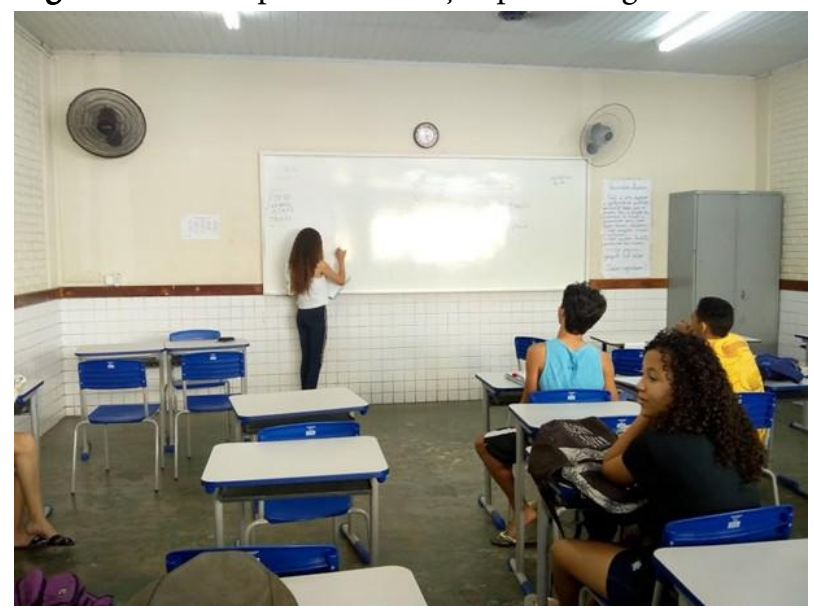

Fonte: Acervo pessoal, 2018

Para o momento da aplicação, ainda na segunda aula, foi proposto que os alunos criassem suas próprias situações, entrando ainda mais em seu cotidiano. Eles já deveriam criá-las com os conceitos e indicações de força colocados. Também deveriam apresentar para que colegas e professor verificassem e discutissem (figura 2). Assim, além de aplicar na própria situação, os alunos aplicaram os conhecimentos organizados em novas situações criadas pelos colegas.

Figura 2. Apresentação das situações de aplicação

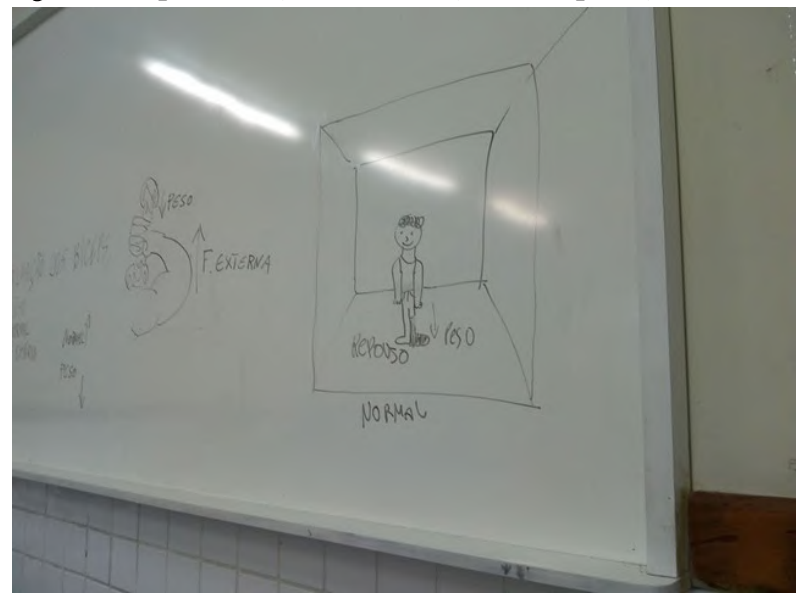

Fonte: Acervo pessoal, 2018 


\section{RESULTADOS}

A participação dos alunos foi ativa, como planejado. No momento em que foram deixados a sós, pela janela podíamos ouvir os debates. Mas a presença do professor não inibiu as discussões. Os alunos apresentavam suas ideias, falavam, argumentavam, iam ao quadro, desenhavam em seus cadernos.

Tanto essa atividade como outras desenvolvidas permitem a aproximação afetiva entre professores e alunos. Prova simples porém significativa disso foi um dos exemplos envolver o professor, de forma que a aluna fez questão de contar à sala toda. Ou seja, os alunos se sentem à vontade para falar do professor e aprender mesmo com situações cotidianas envolvendo-o.

As discussões foram realizadas e os conceitos científicos tiveram espaço nelas. Durante a problematização, surgiram ideias muito presentes no senso comum, de que força está associada apenas ao esforço de alguém, que apenas pessoas realizam força. Essa ideia ia sendo contestadas ao longo da problematização e sua versão científica levantada durante a organização. Ao final, na aplicação do conhecimento, os alunos já eram capazes de perceber que não apenas humanos realizam força, mas todas as interações podem ser entendidas por meio do conceito de força e suas implicações no movimento dos corpos (DOCA, BISCUOLA, BÔAS, 2013)

\section{REFERÊNCIAS}

DELIZOICOV, D. Problemas e problematizações. In: Maurício Pietrocola. Ensino de Física: conteúdo, metodologia e epistemologia em uma concepção integradora. Ilhéus: UESC, 2001.

DOCA, R.H.; BISCUOLA, G.J.; BÔAS, N.V.. Física 1. São Paulo: Editora Saraiva, 2013. 
